\title{
Beware of multiple names in database linkage research: prevalence of aliases in female prison population
}

\author{
Ruth Elwood Martin, T Gregory Hislop, Garry D Grams, Veronika Moravan, Betty Calam
}

A common strategy for health services research involves linking the records held in administrative databases using personal name data. Studies may also require following individuals over time, again necessitating names.

Multiple names became a dilemma in our research of a screening intervention for female prisoners in British Columbia, Canada, such that we excluded from database linkage those women's records with at least five surnames or at least four first given names. ${ }^{1}$ We found no reports in the health services research literature regarding multiple names. We describe the distribution of aliases within a female prison population and compare the sociodemographic characteristics of prisoners with and without aliases. We discuss the implications for healthcare studies involving people with multiple names.

\section{Participants, methods, and results}

We investigated the multiple names of 847 female prisoners at the Burnaby Correctional Centre for Women in 2000-1. These women were serving federal sentences (at least two years, including life sentences), provincial sentences (less than two years), or remanded to custody (awaiting sentencing).

We took data from the centre's inmate records for the cervical cancer screening linkage project, ${ }^{1}$ including all known aliases (multiple names) and the following sociodemographic characteristics: age (as a continuous variable), ethnicity (white, Aboriginal, other), education (no high school, high school, post high school), and type of incarceration (remand, sentenced). We grouped the names into the following classes: surnames, first names, and full names (first names and surname). We used a Poisson model to assess the significance of association of the sociodemographic characteristics with numbers of names (starting at zero for one name) for each class. We used backward elimination to check for independent effects of these factors.

The mean number of names was 2.7 for surnames (maximum 21), 2.4 for first names (maximum 23), and 3.5 for full names; $48 \%$ of the inmates had three or more names, and 24\% five or more (maximum 28). Ethnicity and type of incarceration were highly significant for all three classes of name (table; $\mathrm{P}<0.0001$ ). Aboriginal women had more names than any other ethnic groups. Women serving sentences had more names than women in remand. Level of education had an inverse relationship with number of first names $(\mathrm{P}=0.003)$ and full names $(\mathrm{P}<0.03)$. The number of names increased with age for surnames and full names $(\mathrm{P}<0.0001)$ and first names $(\mathrm{P}=0.04)$.

Multivariable Poisson models showed ethnicity, incarceration type, and age to be significant predictors for numbers of surnames and full names $(\mathrm{P}<0.0001)$ and first names $(\mathrm{P}<0.0001, \mathrm{P}<0.0001$ and $\mathrm{P}<0.01$ respectively) after adjusting for covariates. Education level was not a significant independent predictor for multiple names.

Association of number of surnames, first names and full names with ethnicity, education level, incarceration type and age for female prisoners at Burnaby Correctional Centre for Women

\begin{tabular}{|c|c|c|}
\hline & $\begin{array}{c}\text { Estimated mean }(95 \% \mathrm{Cl}) \\
\text { number of names }\end{array}$ & $P$ value \\
\hline \multicolumn{3}{|l|}{ Surnames } \\
\hline \multicolumn{3}{|l|}{ Ethnicity: } \\
\hline White & 2.5 (2.3 to 2.7$)$ & \multirow[t]{3}{*}{$<0.0001$} \\
\hline Aboriginal $^{*}$ & 3.4 (3.1 to 3.7 ) & \\
\hline Other & 1.9 (1.6 to 2.4$)$ & \\
\hline \multicolumn{3}{|l|}{ Education: } \\
\hline No high school & 2.8 (2.5 to 3.2$)$ & \multirow[t]{3}{*}{0.2} \\
\hline High school & 2.8 (2.6 to 3.0$)$ & \\
\hline Post high school & 2.4 (2.0 to 2.8 ) & \\
\hline \multicolumn{3}{|l|}{ Incarceration: } \\
\hline Remand $\dagger$ & 2.2 (2.0 to 2.4) & \multirow[t]{2}{*}{$<0.0001$} \\
\hline Sentenced & 3.1 (2.9 to 3.3$)$ & \\
\hline \multicolumn{3}{|l|}{ Age (years)ł: } \\
\hline 20 & 2.3 (2.3 to 2.3 ) & \multirow[t]{3}{*}{$<0.0001$} \\
\hline 30 & 2.6 (2.5 to 2.9 ) & \\
\hline 40 & 3.1 (2.7 to 3.6$)$ & \\
\hline
\end{tabular}

\section{First names}

\begin{tabular}{lll}
\hline Ethnicity: & & \\
\hline White & $2.2(2.1$ to 2.4$)$ & $<0.0001$ \\
\hline Aboriginal $^{*}$ & $3.1(2.8$ to 3.4$)$ &
\end{tabular}

\begin{tabular}{ll}
\hline Aboriginal $^{*}$ & $3.1(2.8$ to 3.4$)$ \\
\hline Other & $1.8(1.5$ to 2.3$)$ \\
\hline Education: &
\end{tabular}

\begin{tabular}{|c|c|c|}
\hline No high school & 2.7 (2.5 to 3.1$)$ & 0.003 \\
\hline High school & 2.4 (2.3 to 2.6$)$ & \\
\hline Post high school & 2.0 (1.7 to 2.3$)$ & \\
\hline \multicolumn{3}{|l|}{ Incarceration: } \\
\hline Remand† & 2.1 (1.9 to 2.3$)$ & $<0.0001$ \\
\hline Sentenced & 2.7 (2.5 to 2.9$)$ & \\
\hline \multicolumn{3}{|l|}{ Age (years)ł: } \\
\hline 20 & 2.3 (2.3 to 2.3$)$ & 0.04 \\
\hline 30 & 2.4 (2.3 to 2.6$)$ & \\
\hline 40 & 2.6 (2.3 to 3.0$)$ & \\
\hline
\end{tabular}

\section{Full names}

Ethnicity:

\begin{tabular}{|c|c|c|}
\hline White & 3.1 (2.9 to 3.4 ) & $<0.0001$ \\
\hline Aboriginal $^{*}$ & 4.5 (4.1 to 4.9 ) & \\
\hline Other & 2.4 (2.0 to 3.1$)$ & \\
\hline \multicolumn{3}{|l|}{ Education: } \\
\hline No high school & 3.9 (3.4 to 4.3 ) & 0.03 \\
\hline High school & 3.5 (3.2 to 3.7$)$ & \\
\hline Post high school & 2.9 (2.4 to 3.5 ) & \\
\hline \multicolumn{3}{|l|}{ Incarceration: } \\
\hline Remand† & 2.8 (2.6 to 3.1$)$ & $<0.0001$ \\
\hline Sentenced & 3.9 (3.7 to 4.2$)$ & \\
\hline \multicolumn{3}{|l|}{ Age (years) $\ddagger$ : } \\
\hline 20 & 2.9 (2.9 to 3.0$)$ & $<0.0001$ \\
\hline 30 & 3.4 (3.1 to 3.7) & \\
\hline 40 & 4.0 (3.4 to 4.6 ) & \\
\hline
\end{tabular}

${ }^{*}$ We use the term Aboriginal as a collective name to describe the original peoples of North America and their descendents.

†The prisoner is awaiting sentencing, which may be overnight or a few days or several weeks.

†Calculated from Poisson model estimated parameters: surnames (intercept $=0.1810, \lambda=0.0245$ ) first names (intercept $=0.2250, \lambda=0.0101$ ) full names (intercept $=0.6045, \lambda=0.0209$ ) with intercept at 17 years of age.
Department of Family Practice, Mather Building, 5804 Fairview Crescent, University of British Columbia, Vancouver, V6T 1Z3, British

Columbia, Canada

Ruth Elwood

Martin

clinical associate professor

Cancer Control

Research, BC

Cancer Agency,

Vancouver,

V5Z 4E6

T Gregory Hislop senior epidemiologist

Department of

Family Practice,

University of British

Columbia

Garry D Grams assistant professor

Population and Preventive

Oncology, BC

Cancer Agency

Veronika Moravan statistician

Department of Family Practice,

University of British

Columbia

Betty Calam

associate professor

Correspondence to:

R Elwood Martin

ruth.martin@

familymed.ubc.ca

BMJ 2005;331:335-6 


\section{What is already known on this topic}

The prevalence or distribution of multiple names in women is unknown

\section{What this study adds}

Multiple names are common in certain subgroups of female prison inmates, which raises important challenges for health services provision and database linkage research

\section{Comment}

This first study of multiple names in women prisoners raises caution about representativeness and generalisability of research that uses names for linking databases. Women who were older, Aboriginal, and with longer prison sentences were more likely to be excluded from our database linkage because of multiple names. ${ }^{1}$

Many women seek their healthcare while in prison. Follow-up is often required after release from prison. Healthcare providers should be aware of multiple names to avoid loss to follow-up in the community.

Men also report multiple names. In a study of US male prisoners, $31 \%$ had changed their names at some time for intentional deception. ${ }^{2}$ Aliases were associated with age, ethnicity, education, and level of criminality in inmates in New Zealand. ${ }^{3}$ Male forensic patients with multiple names had more psychiatric illness. ${ }^{4}$

Name change is done for various reasonsmarriage, alias, pseudonym, manipulation, fraud, psychosis, amnesia, and factitious disorder. "Ethnic naming" is sometimes done to resolve competing national and ethnic identities, to honour family and ancestors, or to seek new purpose when not accepted by the prevalent culture. Ethnic naming may be a common reason for multiple names among Aboriginal people, who comprised a sizeable proportion of our study group. Our findings could have implications for provision of health services and database linkage research among ethnic and Aboriginal communities not limited to the prison population.

We thank the Cervical Cancer Screening Program at the British Columbia Cancer Agency, the Corrections Branch of the Ministry of Public Safety, and The Solicitor General for giving approval for this study and for giving information needed for the linkage.

Contributors: Dennis Wardman, community medicine specialist, First Nations and Inuit Health Branch, reviewed and commented on early versions of the manuscript and approved the final version for publication. TGH, GDG, BC, and REM conceived the design, implementation, and evaluation of the cervical cancer screening intervention, which led to the writing of this paper. TGH, GDG, and REM wrote the initial versions of this manuscript and all authors were involved in editing subsequent versions. VM linked the databases and did the analysis for this paper; she was also involved in the writing and editing. REM is guarantor.

Funding: British Columbia Medical Services Foundation.

Competing interests: None declared.

Ethical approval: University of British Columbia.

1 Martin RE, Hislop TG, Grams GD, Calam B, Jones E, Moravan V. The Evaluation of a cervical cancer screening intervention for prison inmates. Can J Public Health 2004;95:285-9.

2 Harry B. Diagnostic study of the criminal alias. I Forensic Sci 1986;31:1023-8.

3 Boshier RF. Henry Forger: a psychological study of the criminal alias. Aust N Z J Criminol 1977;10:17-25.

4 Vollm B, Jamieson L, Gordon H, Taylor P. Name change among offender patients: an English high security hospital sample. Crim Behav Ment Health 2002;12:269-81.

5 Rendleman N. False names. West J Med 1998;169:318-21.

(Accepted 2 July 2005)

\section{A memorable patient}

\section{The unwanted diagnosis}

He was a fit intelligent 74 year old accountant who walked five miles every day, lived for his family and dogs, and had worked hard for his comfortable life. He was afraid of doctors and never saw one until absolutely necessary - as demonstrated by his two strangulated inguinal hernias.

As I drove to his house, I had the feeling that my life was about to change. It was a bitter February day with a biting north wind blowing flurries of snow. I entered the house and breathed a sigh of relief when everything seemed normal. Then his words: "I have two minor medical problems, doctor: RSI and leg weakness." He always was useless at medical matters.

I looked in horror as he showed me a flaccid left wrist and bilateral leg weakness, but worst of all was the widespread muscle fasciculations. I knew the diagnosis in an instant-motor neurone disease. A swift admission was arranged, and I watched helplessly as he saw doctor after doctor and had test after test. Every day his strength slipped away, and I sat with him watching his muscles twitch madly. No one would admit the true situation, and I had to pretend for three weeks that the outcome could be positive. Finally, he was discharged and declined to know the name of the condition when he saw the despair in my eyes and realised it would be his last illness.

I knew it would be quick. I cared for him and acted as his doctor over the next four weeks. I joked that he had his own personal physician like the queen. We discussed life's important issues. However, when I asked for help in his terminal care my request was not taken seriously, and we decided to move him to be nearer doctors who I knew would give him the morphine he needed. His son was told in black and white the speed of decline and spent all day before the death with his father. I constantly thought about ways to relieve the patient's mental suffering. He and I were inconsolable.

He died in a car as he travelled to my house. He was dressed and shaved and just fell asleep, happy in the knowledge that I would look after all his medical needs. He was talking about this a few minutes before his death.

Oh yes, the patient's name-my wonderful dad.

Sue Warren general practitioner, Poole, Dorset (jhswmhjh@onetel.com)

We welcome articles up to 600 words on topics such as A memorable patient, A paper that changed my practice, My most unfortunate mistake, or any other piece conveying instruction, pathos, or humour. Please submit the article on http:// submit.bmj.com Permission is needed from the patient or a relative if an identifiable patient is referred to. We also welcome contributions for "Endpieces," consisting of quotations of up to 80 words (but most are considerably shorter) from any source, ancient or modern, which have appealed to the reader. 